\title{
The enhancement of nuclear receptor transcriptional activation by a mouse actin-binding protein, alpha actinin 2
}

\author{
S M Huang, C J Huang, W M Wang ${ }^{1}$, J C Kang ${ }^{2}$ and W C Hsu \\ Department of Biochemistry, National Defense Medical Center, Taipei, Taiwan 114, Republic of China \\ ${ }^{1}$ Department of Dermatology, Tri-Service General Hospital, Taipei, Taiwan 114, Republic of China \\ ${ }^{2}$ Division of Colon and Rectum Surgery, Tri-Service General Hospital, Taipei, Taiwan 114, Republic of China \\ (Requests for offprints should be addressed to S M Huang; Email: shihming@ndmctsgh.edu.tw)
}

\begin{abstract}
The p160 coactivators, steroid receptor coactivator 1 , glucocorticoid receptor interacting protein 1 (GRIP1) and the activator of thyroid and retinoic acid receptor, have two activation domains, AD1 and $A D 2$, which transmit the activation signal from the DNA-bound nuclear receptor to the chromatin and/or transcription machinery. In screening for mammalian proteins that bind the AD2 of GRIP1, we identified a mouse actin-binding protein, alpha actinin 2 (mACTN2). mACTN2 was expressed in the heart, skeletal muscle, lung, brain and testis, but there was no expression in the spleen, liver or kidney. Interestingly, the expression level of mACTN2 in the developing embryo depended on the embryonic stage. We further demonstrated that mACTN2 could enhance two transactivation activities of GRIP1, which in turn could enhance the homodimerization of mACTN2. Importantly, mACTN2 not only served as a primary coactivator for androgen receptor, estrogen receptor and thyroid receptor activities, but also acted synergistically with GRIP1 to enhance these nuclear receptor (NR) functions. However, the NR binding motif, LXXLL, conserved in mACTN2 and other actinin family proteins, might be a dispensable domain for its coactivator roles in NRs. These findings suggested that mACTN2 might play an important role in GRIP1-induced NR coactivator functions.
\end{abstract}

Journal of Molecular Endocrinology (2004) 32, 481-496

\section{Introduction}

Nuclear receptors (NRs) make up a family of transcription factors that regulate gene expression in a ligand-dependent manner (Tsai \& O'Malley 1994, Beato et al. 1995, Mangelsdorf \& Evan 1995). Members include the receptors for steroid, thyroid, retinoid and vitamin D hormones. In addition, some unidentified regulatory ligands bind to so-called orphan receptors of the NR superfamily. A highly conserved DNA-binding domain (DBD) located in the central portion of the polypeptide chain is the hallmark of all NR structures. The hormone-binding domain, which is conserved to a lesser extent than the DBD, is a large C-terminal domain. In addition to binding hormone, the hormone-binding domain also contains an important and highly conserved activation function, AF-2, which is one of the two domains primarily responsible for the activation of transcription by hormone-activated DNA-bound NR. The other activation function, AF-1, found in the N-terminal domain of most NRs, is not conserved in length or sequence. The relative importance of AF-1 and AF-2 varies among different $\mathrm{NRs}_{\mathrm{s}}$ and can be influenced by ligand, cell type and target gene promoter. Most ligands that bind NRs as homo- or heterodimers activate transcription by binding to enhancer elements in the promoters of target genes. However, some members of the NR family regulate transcription by binding to other classes of DNA-bound transcription factors. In addition to gene activation, a subset of $\mathrm{NRs}_{\mathrm{s}}$, including thyroid receptor (TR) and retinoic acid receptor, can actively repress target genes in the presence or absence of ligand binding, while many NRs inhibit 
transcription in a ligand-dependent manner by antagonizing the transcriptional activities of other classes of transcription factors. The mechanism of transcriptional regulation by the DNA-bound NRs appears to involve their ability to recruit a variety of coregulatory proteins, including coactivators and corepressors (Glass \& Rosenfeld 2000). Generally, coactivators are not DNA-binding proteins, but rather are recruited to the promoter through protein-protein interaction with the transcriptional activators. They may be thought of as adaptors or components in a signaling pathway that transmits transcriptional activation signals from DNA-bound activator proteins to the chromatin and transcription machinery. Transcriptional corepressors could involve competition for limiting factors, displacement of positive factors, or the generation of a chromatin structure that limits promoter accessibility by histone deacetylation. Therefore, the latest working model of NRs is an initial association with transcriptional corepressors and subsequent ability to recruit coactivators in response to ligands and other signals (Feng et al. 1998).

NR coactivator proteins, recruited by ligandbound NRs or their activation functions, modify local chromatin structure by catalyzing covalent histone modifications and directly assembling and/or stabilizing the transcription preinitiation complex. A growing list of putative NR coactivators has been identified by their ability to bind and/ or enhance the activity of NRs. Three major protein families function in a coactivator complex associated with the DNA-bound NRs: the p160 coactivators, cAMP-responsive element-binding protein-binding protein (CBP)/p300, and p300/ CBP-associated factor (p/CAF) (Freedman 1999, McKenna et al. 1999, Glass \& Rosenfeld 2000). The p160 coactivators include steroid receptor coactivator 1, glucocorticoid receptor interacting protein 1 (GRIP1) and the activator of thyroid and retinoic acid receptor. They bind directly to the hormone-binding domain of NRs by their LXXLL motifs, where $\mathrm{L}$ is leucine and $\mathrm{X}$ is any amino acid, and enhance NR AF-2 activity in the presence of appropriate ligands (Heery et al. 1997, Feng et al. 1998, McInerney et al. 1998). The pl60 coactivators also bind the $\mathrm{AF}-1$ region of some NRs, including progesterone receptor, estrogen receptor (ER), TR, mineralocorticoid receptor and androgen receptor (AR), and thereby enhance these AF-1 functions (Oñate et al. 1998, Webb et al.
1998, Bevan et al. 1999, Ma et al. 1999, Tremblay et al. 1999, Fuse et al. 2000, Oberste-Berghaus et al. 2000). CBP, p300 and p/CAF bind directly to the $\mathrm{NR}$ and to the p160 coactivators (Voegel et al. 1996, Yao et al. 1996, Chen et al. 1997, Torchia et al. 1997, Blanco et al. 1998, Ma et al. 1999). The histone acetyltransferase activity of these coactivators can acetylate histones, transcriptional activators and components of the transcription initiation complex, leading to the proposal that $\mathrm{CBP}$ and p300 serve as platforms to integrate the effects of multiple signaling pathways on many different transcriptional activator proteins (Chakravarti et al. 1996, Kamei et al. 1996, Ogryzko et al. 1996, Swope et al. 1996, Goodman \& Smolik 2000, Strahl \& Allis 2000).

The p160 coactivators have two activation domains, $\mathrm{AD} 1$ and $\mathrm{AD} 2$, which transmit the activating signal from the DNA-bound NR to the chromatin and/or transcription machinery (Voegel et al. 1998, Ma et al. 1999). The function of AD1 results from its ability to bind CBP and/or p300 and transmission of its activating signal by the acetylation activity of CBP and/or p300 on the chromatin and/or transcription machinery. Hence, CBP or p300 serves as a secondary coactivator of NRs because CBP or p300 can be recruited to the promoter by its interaction with the primary p 160 coactivators. AD2 functions by an unknown mechanism that is independent of CBP and p300 (Yao et al. 1996, Voegel et al. 1998). Recently, coactivator-associated arginine methyltransferase 1 (CARM1), an intrinsic arginine methyltransferase, was found to play an important role in $\mathrm{AD} 2$ activation by direct interaction with $\mathrm{AD} 2$, implying the arginine methylation modification on the chromatin and/or transcription machinery (Chen et al. 1999). Other protein methyltransferases similar to the GRIP1-dependent coactivator of CARM1 may serve as secondary NR coactivators and synergistically enhance NR functions with the coexpression of CARM1 according to their histone or substrate specificities (Koh et al. 2001). Furthermore, the cross-talk of $\mathrm{ADl}$ and $\mathrm{AD} 2$ activations may occur through the functional interaction between CARM1 and p300 in NR functions (Chen et al. 2000). A zinc-finger protein that regulates apoptosis and cell cycle arrest (Zacl), one of the proteins interacting with $\mathrm{AD} 2$ of the p160 coactivator, could serve as a primary coactivator or repressor of NR activity, and its 
functions depend on the type of NR, promoter context and cell context (Spengler et al. 1997, Huang \& Stallcup 2000).

In this study, which is a continuation of our previous screening work (Chen et al. 1999, Huang \& Stallcup 2000), we screened a mouse 17-day embryo cDNA library, using the yeast two-hybrid system to search for additional components of the p160 coactivator complex that bind to the AD2 domain of GRIP1. This resulted in the identification of a mouse alpha actinin 2 protein, mACTN2. mACTN2 might work as a primary coactivator for NRs through the recruitment by NRs. mACTN2 also acts synergistically with GRIP1 to enhance NR functions through its interaction with and enhancement of the GRIP1 transactivation activity. Furthermore, the conserved LXXLL motif in mACTN2 and other related cytoskeletal proteins may have implications in the understanding of the cross-talk between cytoskeletal organization and NR functions through their roles in NR coactivator networks.

\section{Materials and methods}

\section{Isolation of the mACTN2 cDNA clone}

A partial mACTN2 cDNA clone $(1 \cdot 8 \mathrm{~kb})$ was isolated by using the yeast two-hybrid system, as described previously (Chen et al. 1999), to screen a mouse 17-day embryo cDNA library for clones encoding proteins that bind to the C-terminal region (amino acids 1121-1462) of GRIP1. The full-length coding region of mACTN2 was synthesized by PCR, using the same mouse embryo library as template, a $5^{\prime}$ sense primer 5'-TTGAATTCATGAATCAGATAGAGCGGG GC-3' (underlined is translation start codon) representing the $5^{\prime}$ end of the mACTN2 coding sequence from our identified mRNA sequences based on hACTN2 (M86406), and an expressed sequence tag (EST) (accession no. AI1 19198), and a 3' antisense primer 5'-TTCTCGAGTTAGAGGT CGGTTTCGCGGTAG-3' (underlined is translation stop codon) representing the $3^{\prime}$ end of the coding region from the partial mACTN2 clone isolated from our yeast two-hybrid screen. All cDNA clones were sequenced by the dideoxy chain termination method, using a Sequenase version $2 \cdot 0$ DNA sequencing kit (United States Biochemical, $\mathrm{OH}$, USA), or by ABI automatic sequencer. The
mACTN2 sequence is deposited in GenBank file AY036877.

\section{The tissue distribution of mACTN2 mRNA}

A pair of gene-specific mACTN2 PCR primers (a 5' sense primer 5'-TTGAATTCATGAATCAG ATAGAGCGCGGG-3' and a $3^{\prime}$ antisense primer 5'-TTGTGGAGCTGATTGTCTTGATTCACA GC-3' encoding a truncated mACTN2 from amino acids 1-280, $840 \mathrm{bp}$ ) was used for a PCR amplification to analyze the mACTN2 tissue expression pattern in a mouse multiple-tissue cDNA (MTG) panel (no. K1423-1, Glontech). The PCR analysis was performed according to the manufacturer's protocol (PT3158-1, Clontech, CA, USA). The PGR cycling parameters for mACTN2 and G3 PDH mRNAs were $94{ }^{\circ} \mathrm{C}$ for $30 \mathrm{~s}, 58{ }^{\circ} \mathrm{C}$ for $30 \mathrm{~s}$ and $72{ }^{\circ} \mathrm{C}$ for $60 \mathrm{~s}$ cycled 30 times in a Perkin-Elmer 480 thermal cycler. All PGR experiments were repeated at least two times.

\section{Plasmids}

The complete mACTN2 coding region (codons 1-894) and other mACTN2 constructs (codons 1-280, 281-700 and 701-894) were synthesized by PCR and subcloned into the EcoRI and XhoI sites of vector pSG5.HA, which has promoters for expression in vitro and in mammalian cells, and provides an N-terminal HA-tag for the expressed protein (Chen et al. 1999). The pSG5.HA vectors coding for full-length GRIP1 (codons 5-1462) and GRIP1 (codons 5-1121) were described previously (Huang \& Stallcup 2000); for GRIP1 (codons 563-1121) was cloned into an EcoRI-SalI fragment into the EcoRI and XhoI sites of vector pSG5.HA. Vectors encoding Gal4 DBD and VP16 AD fused to various fragments of mACTN2 were constructed by inserting EcoRI-XhoI fragments of the appropriate PCR-amplified mACTN2 cDNA into the EcoRI and SalI sites of the pM and pVP16 vectors (Clontech). Vectors encoding Gal4 DBD fused to various fragments of GRIP1s were constructed by inserting EcoRI-SalI fragments of the appropriate PCR-amplified GRIP1 cDNA into the EcoRI and SalI sites of the pM vector. Reporter genes, mouse mammary tumor virus promoter containing luciferase coding region (MMTV-LUC), MMTV(ERE)-LUG, EREII-LUG, MMTV(TRE)LUC, and GKl containing Gal4 response 
elements, were described previously (Umesono $\mathrm{et} \mathrm{al}$. 1989, Paech et al. 1997). For expression of NRs in mammalian cells, vectors pSVAR 0 (Brinkmann

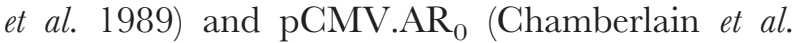
1994) for human AR, pHE0 (Green et al. 1988) for human ER $\alpha$, and pCMX.hTR $\beta 1$ (Feng et al. 1998) for human TR $\beta 1$ were used as described previously.

Mutation in the LXXLL motif of mACTN2, mACTN2 LXXAA, was introduced into the pSG5.HA.mACTN2 vectors by the method of oligonucleotide-directed mutagenesis using uracilcontaining single-strand DNA (Kunkel et al. 1987) and was verified by sequencing.

\section{Cell culture and transient transfection assays}

For functional assays, HeLa or HeLa S3 cells were grown in DMEM/F-12 supplemented with 10\% charcoal/dextran-treated fetal bovine serum; C2C12 cells (ATCG) were grown in supplemented DMEM medium containing 10\% fetal bovine serum. Transient transfections and luciferase assays were performed in a 24-well culture dish, as described previously (Ma et al. 1999). Total DNA was adjusted to $1 \mu \mathrm{g}$ by adding the necessary amount of pSG5.HA vector. Luciferase activity of the transfected cell extracts is presented as relative light units (RLU) and expressed as the mean and standard deviation from three transfected cultures (Ma et al. 1999). Since the expression of many control vectors that is used to monitor transfection efficiency is influenced by coactivators, internal controls were not used. Instead, reproducibility of observed effects was determined in multiple (at least three) independent transfection experiments.

\section{Immunoprecipitation and immunoblots}

For the association of mACTN2 with GRIP1 or AR, COS7 cells (Gluzman 1981) were transfected with these expression vectors. After transfection, cells were lysed in RIPA buffer $(100 \mathrm{mM}$ Tris-Cl, $\mathrm{pH} 8 \cdot 0,150 \mathrm{mM} \mathrm{NaCl}, 0 \cdot 1 \%$ SDS and $1 \%$ Triton $100)$ at $4{ }^{\circ} \mathrm{C}$. Lysates were subjected to immunoprecipitation with antibodies against either Gal4 DBD or AR (RK5C1 or N-20; Santa Cruz Biotechnology, CA, USA) for $3 \mathrm{~h}$, followed by adsorption to Sepharose-coupled protein A/G (Santa Cruz Biotechnology) for 3 h. Immunoprecipitates were separated by SDS-PAGE and analyzed by immunoblots. For determination of total protein levels, aliquots of cell lysates were subjected to direct immunoblots. Immunoblots were performed as previously described by using $5 \%$ of the extract from lysates for immunoprecipitation, and using antibodies against HA (3F10, Roche, Switzerland), Gal4 DBD or AR (N-20, Santa Cruz Biotechnology). All experiments were repeated at least three times.

\section{Results}

\section{Isolation, sequence and tissue distribution of mACTN2}

The G-terminal region of GRIP1 (amino acids 1121-1462) containing AD2 was used as the bait for screening a mouse 17-day embryo cDNA library in a yeast two-hybrid screening assay. One clone with 1693 unique nucleotides was found to be $90 \%$ identical to the sequence reported in GenBank (accession no. M86406) encoding an alpha actinin 2 from human skeletal muscle (hACTN2) (Beggs et al. 1992). Because our isolated clone lacked a complete $5^{\prime}$ coding region, we used PCR to isolate the missing coding sequences from the same mouse 17-day embryo cDNA library; the upstream primers were designed from the $5^{\prime}$ end of the previously reported hACTN2 and an ETS (GenBank accession no. AI119198), and the downstream primers represented the $3^{\prime}$ end of the coding region of our newly isolated clone. Combined with these two newly synthesized PCR fragments and previously isolated clone, a $2936 \mathrm{bp}$ cDNA clone encoding an 894 codon open reading frame (data not shown, deposited in GenBank accession no. AY036877) was identified to be $99 \%$ identical at the amino acid level to hACTN2. Our overlapped clones for mACTN2, containing a $179 \mathrm{bp}$ fragment and a $75 \mathrm{bp}$ fragment, were in the $5^{\prime}$ and $3^{\prime}$ non-translated regions respectively. Compared with the structural characteristics of hACTN2, the analysis of mACTN2 also showed two copies of the calponin homology domain at the N-terminus (amino acids 38-142 and 151-254), which are responsible for binding to alpha actin through the type I $\left({ }^{40}\right.$ QRKTFTAWGN $\left.{ }^{49}\right)$ and type II ( ${ }^{1 ~}{ }^{4}$ LVSIGAEEIVDGNVKMTLGMIWTII $\left.{ }^{138}\right)$ actinin-type actin-binding motifs in the ACTN family. These calponin homology domains were followed by four copies of the spectrin repeat 
A
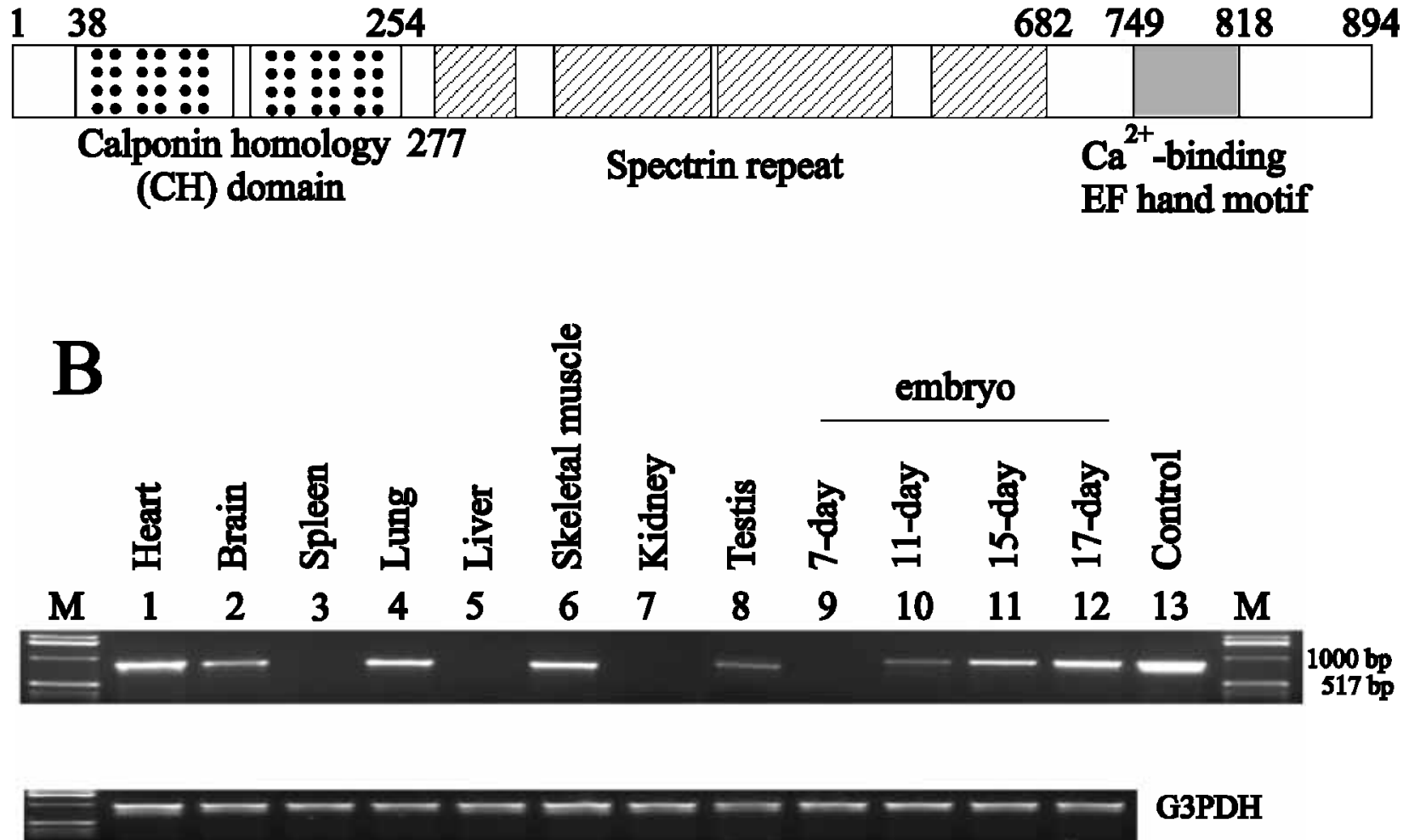

Figure 1 Domains of mACTN2 and its tissue distribution. (A) Sequence motifs in mouse ACTN2 are analyzed and indicated by the ProfileScan Server (http://hits.isb-sib.ch/cgi-bin/PFSCAN). (B) The tissue expression pattern of mACTN2 mRNA and a positive control, G3 PDH mRNA, were performed in a mouse MTC panel (no. K1423-1, Clontech). Two mRNA expression pattern panels were run, and the PCR products analyzed by electrophoresis in a $1 \%$ agarose gel were expected to be an 840 bp fragment for mACTN2 and a 983 bp fragment for G3 PDH. Lanes 1-12 contained the indicated tissue. Lane 13 was a vector control containing mACTN2 ${ }_{1-280}$ as a positive control, and lane $\mathrm{M}$ was a DNA ladder. We observed a similar expression pattern in two independent experiments.

(amino acids 277-331, 368-470, 479-588 and 604-682) and one $\mathrm{Ca}^{2+}$-binding $\mathrm{EF}$ hand motif (amino acids 749-818) (Fig. 1A).

We also analyzed the tissue expression pattern of mACTN2 mRNA in a mouse multiple tissue cDNA panel (Clontech, MTC, no. K1423-1) by PCR analysis. As shown in Fig. 1B, the highest mACTN2 mRNA expression was found in heart, lung and skeletal muscle (lanes 1, 4 and 6), whereas mACTN2 mRNA was expressed to a lesser extent in brain and testis (lanes 2 and 8). mACTN2 gene expression was undetectable in spleen, liver and kidney (lanes 3, 5 and 7). Interestingly, mACTN2 mRNA expression in the embryo gradually increased from day 7 to day 17 (lanes 9-12); however, no expression was found in the 7-day embryonic stage (lane 9). Under the same PCR conditions, a control mRNA, G3PDH, expressed similar mRNA levels in all tissues and embryonic stages (Fig. 1B, bottom panel). Thus, the specificity of mACTN2 in tissues and embryonic stages might be an important factor for mouse development. However, the relationship of the expression in specific tissues and embryonic stages to the functions of mACTN2 remains to be investigated.

\section{Binding of mACTN2 to GRIP1 enhances GRIP1 transactivation activities}

Our previous yeast two-hybrid screening results showed that mACTN2 binds to the C-terminal region of GRIP1 (amino acids 1122-1462; data not 
shown). We performed co-immunoprecipitation experiments to confirm this protein-protein interaction in COS7 cells and further dissected the binding domains of mACTN2 in GRIP1. We used an expression vector containing full-length mACTN2 fused to the yeast Gal4 DNA-binding domain (Gal4 DBD) for pulling down three hemagglutinin A (HA)-tagged GRIP1 fragments (amino acids 5-1121, 563-1462 and 563-1121) with antibody against Gal4 DBD in COS7 cell lysates. The pull-down result showed that mACTN2 bound only to a GRIP1 fragment containing the G-terminal region of GRIP1 (amino acids $1122-1462$ ), such as GRIP1 $1_{563-1462}$, but did not bind to GRIP1 $1_{5-1121}$ or GRIP1 $1_{563-1121}$ in COS7 cells (Fig. 2A, upper panel, lanes 1-3). A similar conclusion was reached in two independent

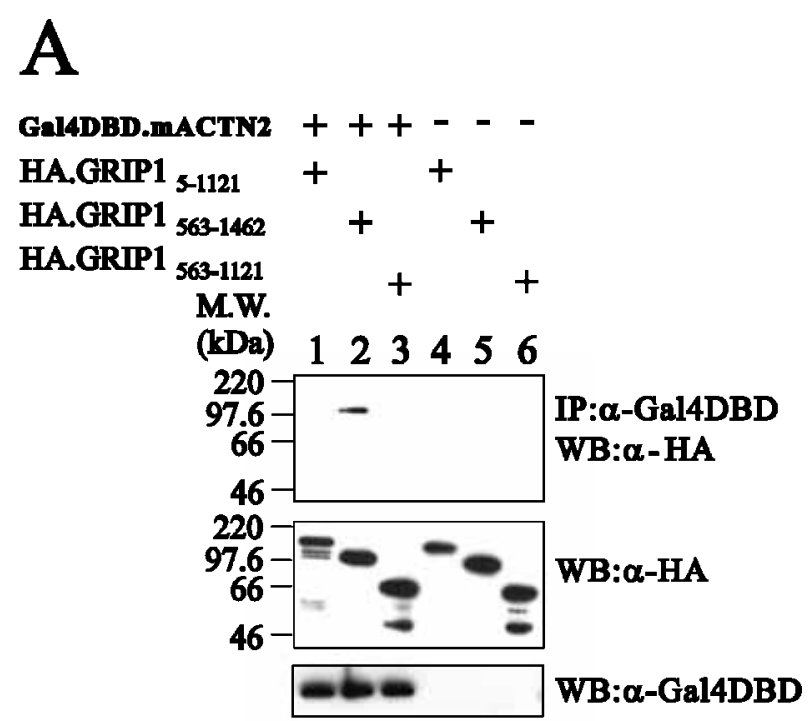

B

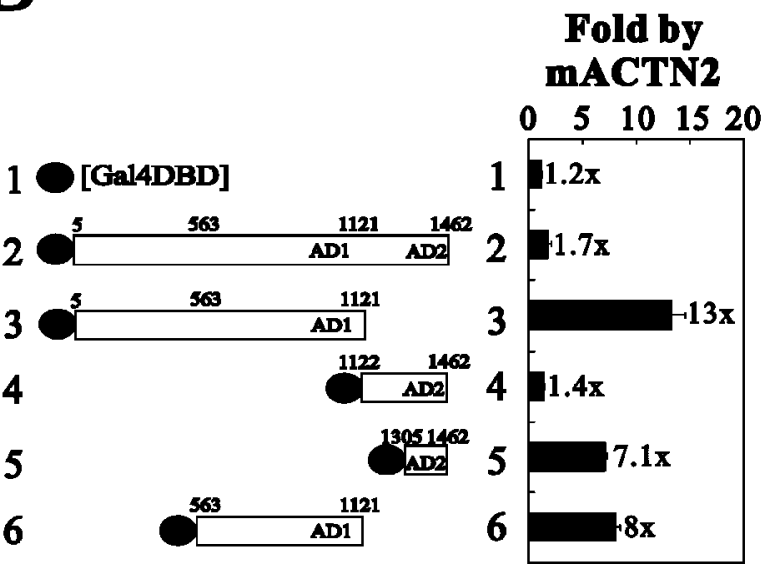

co-immunoprecipitation experiments in COS7 cells (data not shown). We failed to determine the direct binding domains between mACTN2 and GRIP1 using the glutathione $S$-transferase pull-down assay (data not shown). Hence, these findings suggest that mACTN2 might indirectly interact with GRIP1 under in vivo conditions (such as in COS7 cells) and the GRIP1 C-terminal region might be an important region for binding.

Because mACTN2 interacted in vivo with GRIP1 (Fig. 2A), we tested whether mACTN2 could affect the transactivation activity (AD1 and/or AD2) of GRIP1 through various GRIP1 fragments, containing $\mathrm{AD} 1, \mathrm{AD} 2$ or both, fused to the yeast Gal4 $\mathrm{DBD}$, which is capable of activating transcription of a reporter gene containing Gal4 response elements. mACTN2 was able to enhance both the $\mathrm{AD} 1$ and $\mathrm{AD} 2$ transactivation activities of GRIP1 (Fig. 2B; compare histograms 1, 3, 5 and 6). One possible repression domain (amino acids 11221304) in GRIP1 played a steric hindrance role for the regulation of its transactivation activity because full-length GRIP1 and GRIP1 $1_{1122-1462}$ have lower activities than fragments that lack this repression region, such as GRIP1 $1_{5-1121}$ and GRIP1 $1305-1462$ (Huang \& Hsu, unpublished data). Alternatively, mACTN2 might not be able to compete for this repression region and then fail to enhance transactivation activities in full-length GRIP1 or GRIP1 ${ }_{1122-1462}$ (Fig. 2B; compare histograms 1, 2 and 4). In addition, mACTN2 might indirectly

Figure 2 Physical and functional interactions between mACTN2 and GRIP1. (A) COS7 cells were transfected with HA.GRIP1 ${ }_{5-1121}$, HA.GRIP1 $1_{563-1462}$ or HA.GRIP1 ${ }_{563-1121}(5 \mu \mathrm{g})$ in the absence or presence of Gal4 DBD.mACTN2 $(5 \mu \mathrm{g})$. Cell extracts were subjected to immunoprecipitation with anti-Gal4 DBD antibody and then immunoblotted with anti-HA antibody (upper panel) or immunoblotted with anti-HA or anti-Gal4 DBD antibody for $5 \%$ cell extracts (input controls, middle and lower panels) applied in immunoprecipitation. We observed a similar binding pattern in two independent experiments. (B) HeLa S3 cells were treated with $0.4 \mu \mathrm{g}$ mACTN2, $0.3 \mu \mathrm{g}$ Gal4 DBD or various GRIP1 fragments (amino acids 5-1462, 5-1121, 1122-1462, 1305-1462 and 563-1121) fused with Gal4 DBD, and $0.3 \mu \mathrm{g}$ of the GK1 reporter gene, which encodes luciferase and is controlled by Gal4 response elements. Fold activation (indicated above the bars) was calculated by comparing the luciferase activity of each GRIP1 fragment fused with Gal4 DBD cotransfected with mACTN2 to those not cotransfected with mACTN2. The data (B) are based on at least three separate experiments. 
regulate the GRIP1 transactivation activity because mACTN2 failed to interact directly with GRIP1 $_{5-1121}$ or GRIP1 $1_{563-1121}$ (Fig. 2A).

\section{The enhancement of mACTN2 homodimerization by GRIP1}

Figure 2 shows that mACTN2 could enhance GRIP1 transactivation activities through their physical interaction or by unknown mechanisms. We investigated the possible effect of GRIP1 on mACTN2 characteristics, such as homodimerization. In the mammalian two-hybrid system, the transient transfection assays in HeLa cells demonstrated that full-length or other truncated mACTN2 fused to yeast Gal4 DBD (pM) vectors had no transactivation activity when compared with the value of the $\mathrm{pM}$ vector along with the vector containing VP16 activation domain (pVP16) through monitoring the luciferase activity change in the Gal4 responsive element reporter (compare Fig. 3A, closed columns). Subsequently, the full-length mACTN2 was inserted into the pVP16 vector to confirm its homodimerization property and define the major binding region in mACTN2 (compare Fig. 3A, open columns). The full-length mACTN2 demonstrated the strongest proteinprotein interactions (by 463-fold) in all tested ACTN2 fragments (Fig. 3A, histogram 1, open column). However, the region of spectrin repeats (amino acids 281-700, by 13-fold) of mACTN2 was the only truncated fragment involved in mACTN2 dimerization in cells (Fig. 3A; compare histograms 2-4, open columns). Hence, our findings suggest that its proper conformation and the spectrin repeats of mACTN2 are two major factors for its dimerization in cells. We also found a stronger homodimerization property in the fulllength mACTN2 when a higher transfected dose was applied in the mammalian two-hybrid assays (data not shown). Importantly, the combination of pM.ACTN2 and pVP16.ACTN2 was specifically enhanced by the presence of either full-length GRIP1 or C-truncated GRIP1 (GRIP1 $\left.1_{5-1121}\right)$ in the mammalian two-hybrid assays (compare Figs $3 \mathrm{~B}$ and $\mathrm{C}$ ). In the presence of the highest dose of GRIP1 $_{5-1462}$ and GRIP1 $1_{5-1121}$, these interactions were enhanced fourfold and 32-fold respectively (Fig. 3B). However, a similar dose of GRIP1 $1_{5-1462}$ and GRIP1 $1_{5-1121}$ showed no enhancement com- pared with the combination of $\mathrm{pM}$ and pVP16.ACTN2 (Fig. 3C; compare histograms 2-4) or pM.ACTN2 and pVP16 (Fig. 3C; compare histograms 5-7).

\section{The conserved NR binding motif, LXXLL, of mACTN2 and its family proteins}

Of all reported structural domains in the alpha actinin family, we identified one NR binding motif, LXXLL, near to the mACTN2 N-terminus (amino acids 72-76). The LXXLL motif is conserved in all alpha-actinin family proteins, including those from mouse, human, chicken and Drosophila (Fig. 4A). Interestingly, one or more LXXLL motifs could be found in other related family proteins, such as $\beta$-spectrin, plectin and kakapo (Fig. 4A and data not shown). In addition to the conserved LXXLL motif, other highly conserved sequences, covering all reported functional domains in the ACTN family (Fig. 1A), suggest that ACTN family members may have largely redundant functions in the cell. As the LXXLL motif is a signature for NR coactivators (Feng et al. 1998, McInerney et al. 1998), we tested whether mACTN2 could interact with AR through this motif by the coimmunoprecipitation assay in COS7 cells. Our data indicated that wild-type mACTN2, containing an LXXLL motif and a mutation of the LXXLL motif in mACTN2 to LXXAA (A stands for alanine) both bound to AR, but the mutant form had a much weaker ability than wild-type mACTN2 (compare Fig. 4B, lanes 2 and 3 respectively). Hence, our findings suggest that the LXXLL motif might be one of the functional domains for mACTN2 or other ACTN proteins that interact with $\mathrm{AR}$ or other NRs.

\section{mACTN2 is a primary coactivator for NRs and acts synergistically with GRIP1 in NR functions in HeLa cells}

Because mACTN2 could complex with GRIP1 and AR (Figs 2A and 4B), we examined the possibility that mACTN2 could serve as a primary nuclear receptor coactivator. In transient transfection assays, we found that mACTN2 not only served as a primary NR coactivator in AR, ER and TR functions by seven- to eightfold, but also 


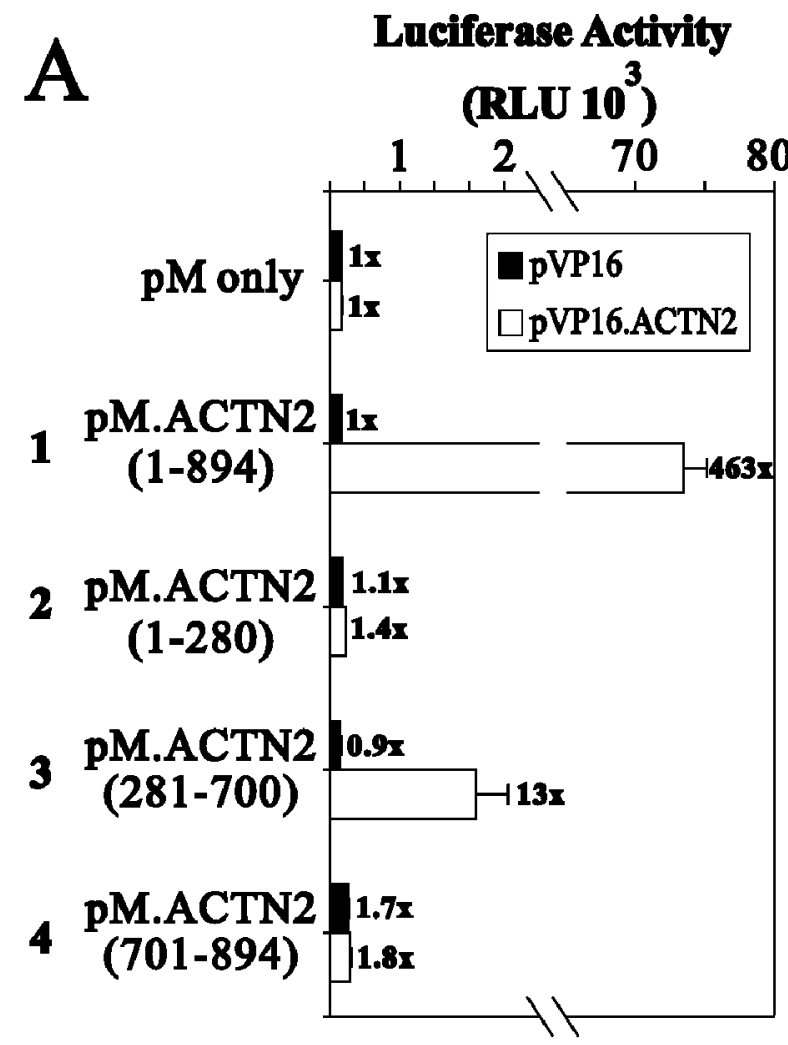

B
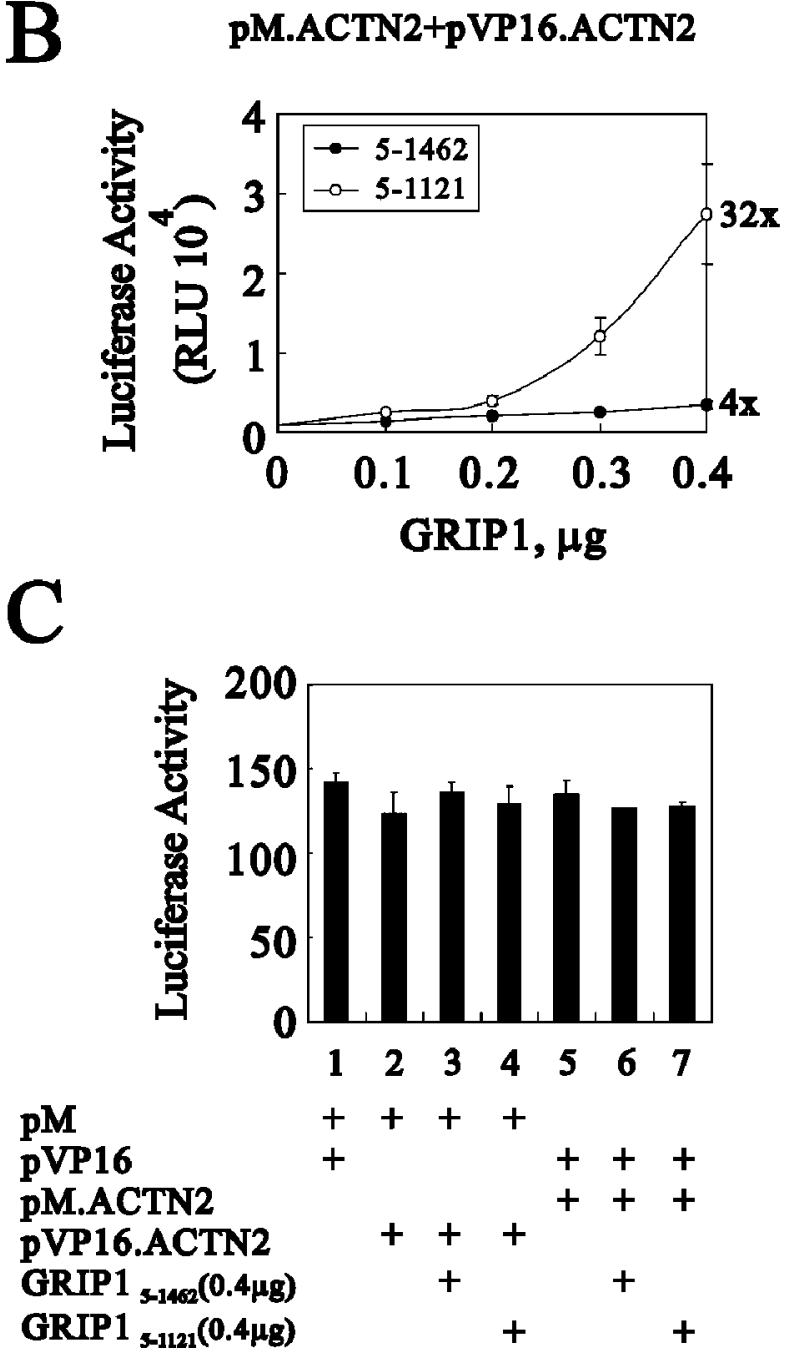

Figure 3 Enhancement of the mACTN2 homodimerization by GRIP1. (A) HeLa S3 cells were transiently transfected with $0.4 \mu \mathrm{g} \mathrm{pM}$ or various pM.mACTN2 fragments paired with $0.4 \mu \mathrm{g} \mathrm{pVP16}$ (closed columns) or PVP16.mACTN2 (open columns), along with the GK1 reporter gene $(0.2 \mu \mathrm{g})$. Luciferase activities of the transfected cell extracts were determined. Numbers above the bars indicate fold activation compared with that of the pM and pVP16. (B) HeLa S3 cells were transiently transfected with $0.2 \mu \mathrm{g}$ pM.mACTN2 and $0.2 \mu \mathrm{g}$ VP16.mACTN2 in the presence of the indicated amount of either GRIP1 $1_{5-1462}$ (solid circles) or GRIP1 ${ }_{5-1121}$ (open circles), along with the GK1 reporter gene $(0.2 \mu \mathrm{g})$. (C) HeLa S3 cells were transiently transfected with $0.2 \mu \mathrm{g} \mathrm{pM}$ or pM.mACTN2 paired with $0.2 \mu \mathrm{g}$ pVP16 or pVP16.mACTN2 in the absence or presence of $0.4 \mu \mathrm{g}$ GRIP1 $1_{5-1462}$ or GRIP1 $_{5-1121}$, along with the GK1 reporter gene $(0.2 \mu \mathrm{g})$. RLU: relative light units. These data $(A, B$ and $C)$ are the average of three experiments (mean \pm S.D.; $n=3$ ).

synergistically interacted with GRIP1 in these three NR functions to $2 \cdot 2-, 6 \cdot 5-$ and $18 \cdot 1$-fold respectively (Fig. 5). The synergy ratio was calculated by dividing the extra activity observed when mACTN2 and GRIP1 were added together, by the sum of the extra activity due to mACTN2 alone, plus the extra activity due to GRIP1 alone.
Our results showed that mACTN2 could synergistically enhance GRIP1-induced NR coactivator functions in the presence of cognate ligands (Fig. 5). We further examined whether the synergy effect of mACTN2 on GRIP1-induced NR coactivator functions depended on each cognate ligand. In transiently transfected assays, we found 
A

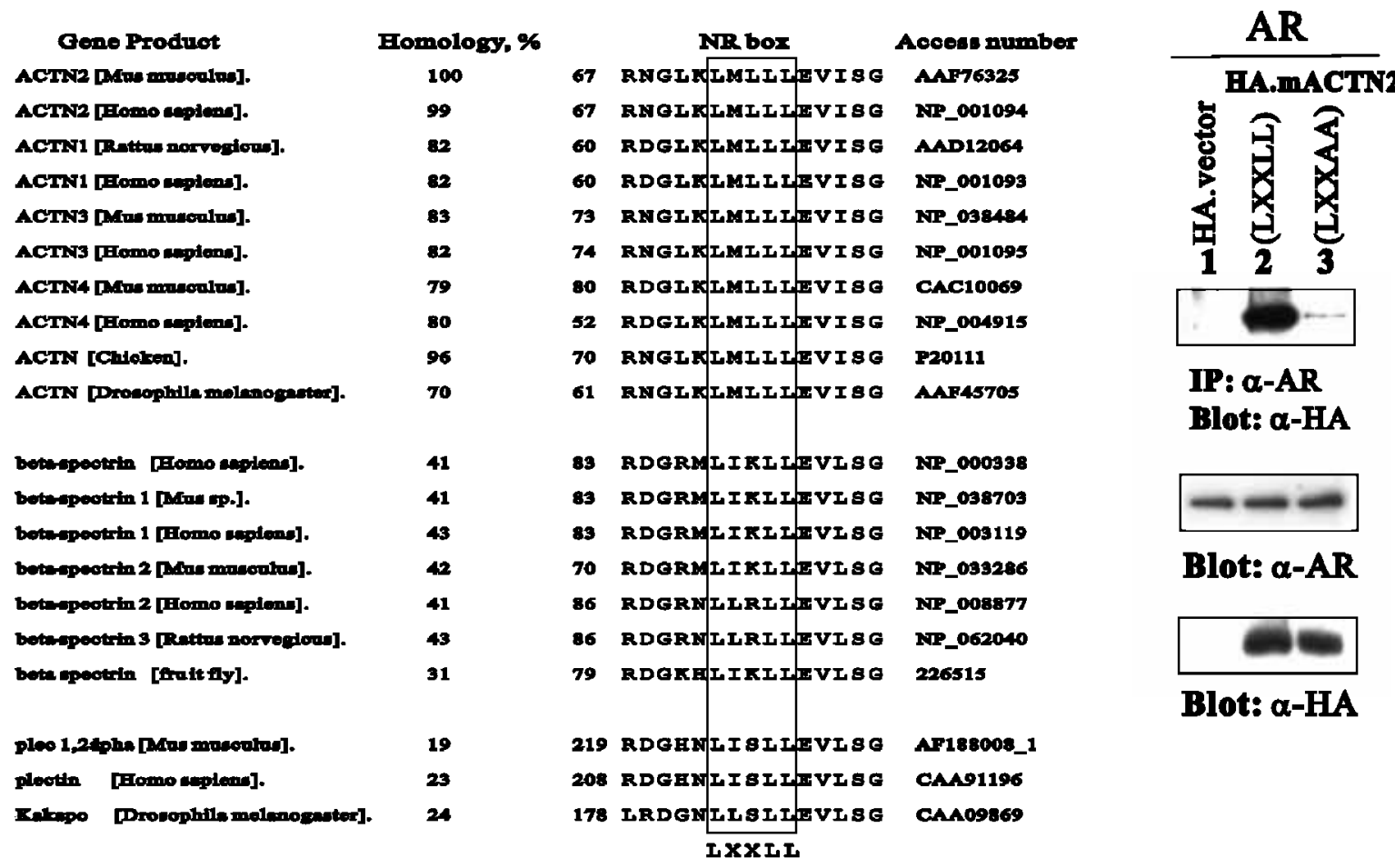

Figure 4 A conserved LXXLL motif in mACTN2 and other family proteins. (A) Analysis of the LXXLL motif from all alpha actinin family proteins, the beta spectrin family and plectin was identical in the consensus sequence. The homology value is the percent similarity in amino acid sequence between full-length mACTN2 and proteins of the actin-binding family from various species. (B) COS7 cells were transfected with HA.ACTN2 ${ }_{1-894}$ (LXXLL), HA.ACTN2 ${ }_{1-894}(L X X A A)$ or HA $(5 \mu \mathrm{g})$ in the presence of androgen receptor (pCMV.AR, $\left.5 \mu \mathrm{g}\right)$. Cell extracts were subjected to immunoprecipitation with anti-AR antibody and then immunoblotted with anti-HA antibody (upper panel) or immunoblotted with anti-AR or anti-HA antibody for $5 \%$ of cell extracts (input controls, middle and lower panels) by immunoprecipitation. We observed a similar binding pattern in two independent experiments.

that mACTN2 could still serve as a primary NR coactivator for AR function (1·7-fold), ER function (sevenfold) and TR function (1·6-fold) (Fig. 6; compare histogram 1, closed and open columns) in HeLa cells, grown in the absence of their appropriate hormones. GRIPl showed 2·7-, 20and twofold enhancements in AR, ER and TR functions respectively (Fig. 6; compare histograms 1 and 2, closed columns). mACTN2 could further synergistically enhance GRIP1 coactivator functions in AR, ER and TR functions to 2.5-, 1·4- and 5.3-fold respectively (Fig. 6; compare histograms 1 and 2). In summary, mACTN2 could synergistically enhance the coactivation of GRIP1 in the absence and presence of the appropriate NR hormones (Figs 5 and 6).
The LXXLL motif is not the only functional domain for mACTN2 coactivation in NR systems

Data in Fig. 5 show that mACTN2 served as a primary NR coactivator as well as a secondary NR coactivator (GRIP1-dependent manner). We used three mACTN2 truncated fragments (amino acids 1-280, 281-700 and 701-894) in HeLa cells to compare their primary and secondary coactivator functions with full-length mACTN2 in these NR functions. The fragment of mACTN2 containing the LXXLL motif (amino acids 1-280) kept most of the primary coactivator function in the AR system, but not in ER and TR (Table 1). The other two fragments expressed at $25-30 \%$ of the level of 
full-length mACTN2 primary coactivator activity in the AR system, but had a similar effect (around $50 \%$ level of full-length mACTN2) to the primary coactivator activity and fragment 1-280 in the ER and TR systems. The synergistic effect (compared with full-length mACTN2) of these three mACTN2 fragments in the GRIP1 coactivator system had similar synergy ratios in the $A R$ and TR systems, but had $50 \%$ of the synergy ratio in the ER system. Considered together, the data in Table 1 suggest that the LXXLL motif in mACTN2 might not be the only functional motif for the primary and secondary coactivator functions in mACTN2 for NR functions.

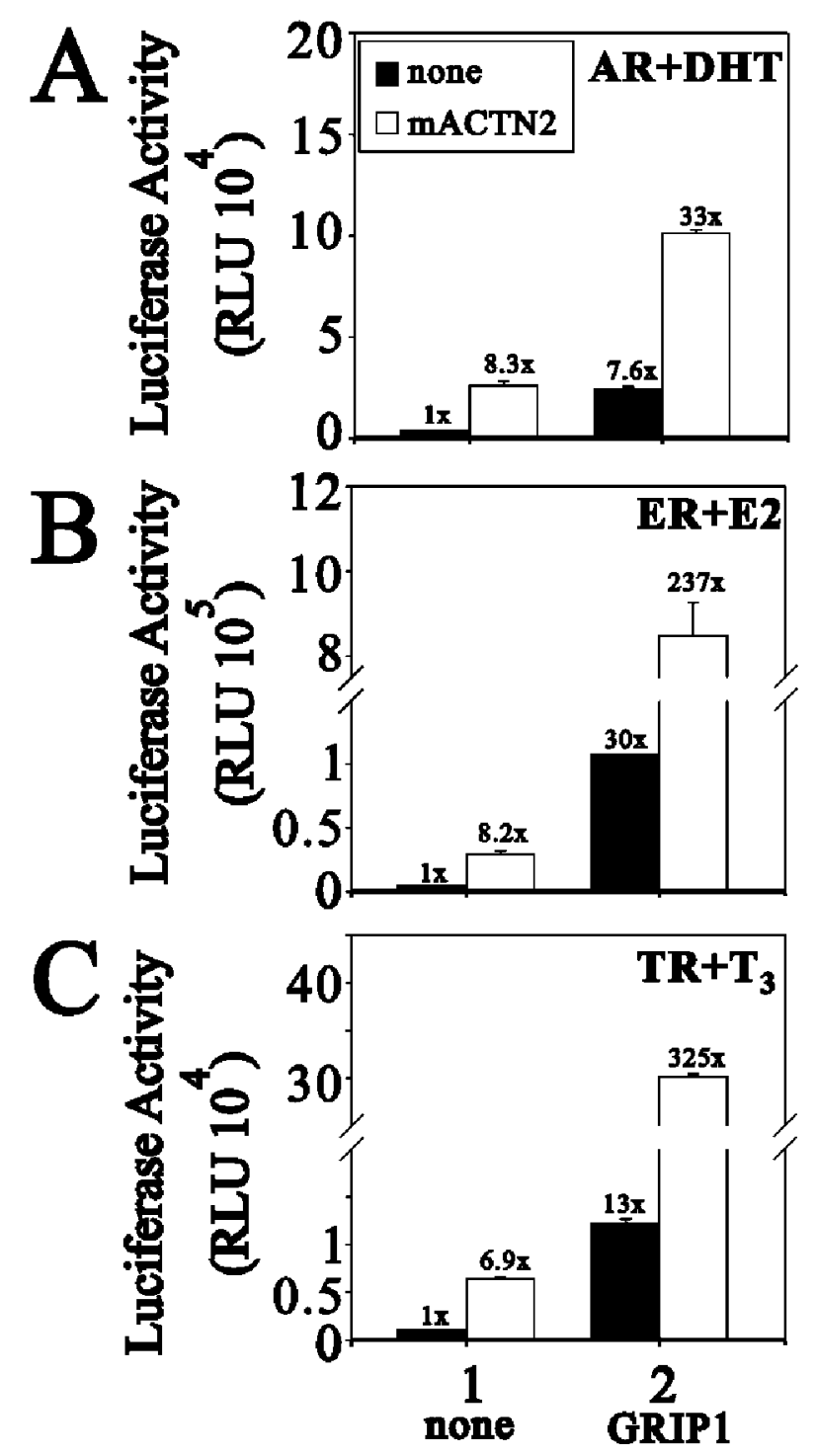

The secondary coactivator functions of mACTN2 is synergistic and dependent on GRIP1 in C2C12 cells

To clarify the NR coactivator role of mACTN2 in muscle and heart development, we used the $\mathrm{C} 2 \mathrm{C} 12$ myoblast cell line, derived from mouse satellite cells, as a model because the cell normally expresses ACTN2 (Hance et al. 1999). In transient transfection assays, we found that mACTN2 (wild-type or LXXAA mutant) synergistically interacted with GRIP1 in AR, ER and TR functions to 10 (or 12)-, 2.5 (or 2.3)- and 22 (or 17)-fold respectively (Figs 7A-C, histograms 5 and 6). mACTN2, but not GRIP1, lost the ability to serve the role of the primary NR coactivator in C2C12 cells (Figs 7A-C; compare histograms 1-4). Similar to the finding in HeLa cells, the LXXLL motif is not the only function motif of mACTN2 in C2C12 cells (Figs 7A-C; compare histograms 5 and 6). In the absence of appropriate NR hormones, mACTN2 and GRIP1 both in combination synergistically enhanced $\mathrm{AR}$ and ER functions in $\mathrm{C} 2 \mathrm{C} 12$ cells

Figure 5 Functional interactions between mACTN2 and GRIP1 on nuclear receptor functions. (A) HeLa cells were transiently transfected with MMTV-LUC reporter gene $(0.3 \mu \mathrm{g})$, pSVAR $(0.2 \mu \mathrm{g})$ encoding $A R$, and $0.25 \mu \mathrm{g}$ pSG5.HA-GRIP1 in the absence (closed columns) or presence (open columns) of mACTN2 $(0.25 \mu \mathrm{g})$. Transfected cultures were grown in $100 \mathrm{nM}$ dihydrotestosterone (DHT), and luciferase activities of the transfected cell extracts were determined. Numbers above the columns indicate fold activity relative to that of hormone-activated AR with no added coactivators.

(B) HeLa cells were transiently transfected with MMTV(ERE)-LUC reporter gene $(0.3 \mu \mathrm{g})$, pHEO $(0.01 \mu \mathrm{g})$ encoding hER $\alpha$, and $0.25 \mu \mathrm{g}$ pSG5.HA-GRIP1 in the absence (closed columns) or presence (open columns) of mACTN2 $(0.25 \mu \mathrm{g})$. Transfected cultures were grown in $100 \mathrm{nM}$ estradiol (E2) and luciferase activities of the transfected cell extracts were determined. Numbers above the columns indicate fold activity relative to that of hormone-activated ER with no added coactivators. (C) HeLa cells were transiently transfected with MMTV(TRE)-LUC reporter gene $(0.3 \mu \mathrm{g})$, pCMX-hTR $\beta 1(0.01 \mu \mathrm{g})$ encoding hTR $\beta 1$, and $0.25 \mu \mathrm{g}$ pSG5.HA-GRIP1 in the absence (closed columns) or presence (open columns) of mACTN2 $(0.25 \mu \mathrm{g})$. Transfected cultures were grown in $100 \mathrm{nM}$ 3,5,5'-triiodo-L-thyronine $\left(T_{3}\right)$ and luciferase activities of the transfected cell extracts were determined. Numbers above the columns indicate fold activity relative to that of hormone-activated TR with no added coactivators. RLU: relative light units. These data $(A, B$ and $C)$ are the average of four experiments (mean \pm S.D.; $n=4$ ). 
(data not shown). All synergy effects by mACTN2 and GRIP1 could not be reached by simply increasing mACTN2 or GRIP1 amount alone to the sum of mACTN2 and GRIP1 (data not shown).

The interesting issue is whether the effect of mACTN2 on non-receptor-dependent promoters exists because of the multiple coactivator functions of some nuclear receptor coactivators. C2C12 and HeLa cells were transfected with a c-Fos promoter (Fos-LUG) and three copies of the cAMP response element $[3 \times(\mathrm{GRE})-\mathrm{LUC}]$ in the presence of GRIP1 or ACTN2 (wild-type or LXXAA mutant), or both in combination (Figs 7D and E). GRIP1 or mACTN2 (wild-type or LXXAA mutant) alone had little or no effect on these tested reporters in these two cells (Figs 7D and E; compare histograms
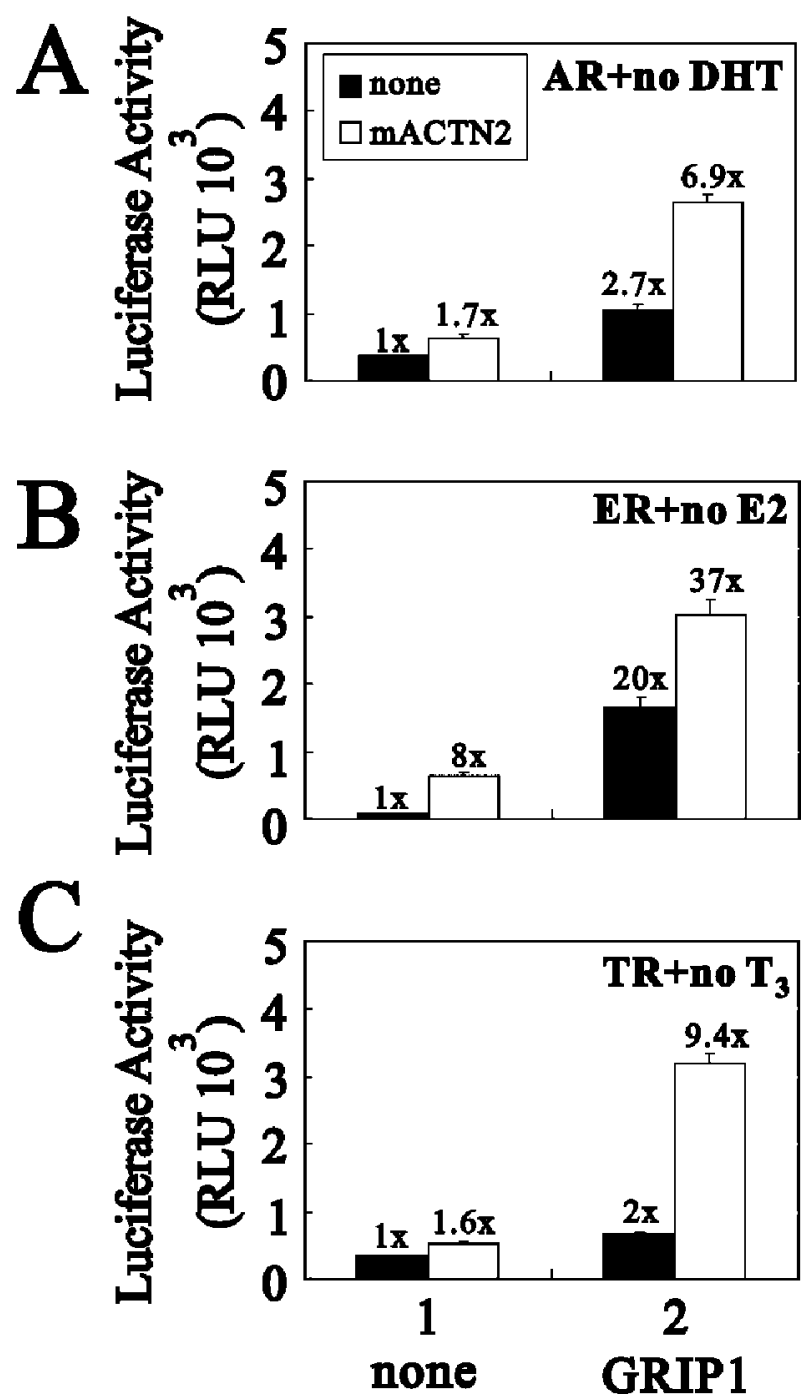

www.endocrinology.org
1-4). The enhancement effects on Fos-LUC and $3 \times(\mathrm{CRE})-\mathrm{LUG}$ reporters caused by mACTN2 (wild-type or LXXAA mutant) and GRIP1 together in C2C12 cells were synergistic (Figs 7D and E; compare histograms 5 and 6 , closed columns), whereas the enhancement effects in HeLa cells on Fos-LUC reporter were synergistic and $3 \times(\mathrm{CRE})$ LUC reporter was additive (Figs $7 \mathrm{D}$ and E; compare histograms 5 and 6 , open columns). Here, our data suggest that mACTN2 and GRIP1 both in combination might serve as a general coactivator for some receptor non-receptordependent transcriptional systems.

\section{Discussion}

\section{The coactivator role of mACTN2 in NR functions}

In this work, we found that mACTN2 could interact with GRIP1 in the yeast two-hybrid

Figure 6 The synergy effect by mACTN2 in GRIP1's NR coactivator functions is independent of cognate ligands. (A) HeLa cells were transiently transfected with MMTV-LUC reporter gene $(0.3 \mu \mathrm{g})$, pSVAR $(0.2 \mu \mathrm{g})$ encoding AR, and $0.25 \mu \mathrm{g}$ pSG5.HA-GRIP1 in the absence (closed columns) or presence (open columns) of mACTN2 $(0.25 \mu \mathrm{g})$. Transfected cultures were grown in DMEM supplemented with $10 \%$ charcoal-treated fetal bovine serum, and luciferase activities of the transfected cell extracts were determined. Numbers above the column indicate fold activity relative to that of $A R$ with no added coactivators. (B) HeLa cells were transiently transfected with EREII-LUC reporter gene $(0.3 \mu \mathrm{g})$, pHE0 $(0.01 \mu \mathrm{g})$ encoding $\mathrm{hER} \alpha$, and $0.25 \mu \mathrm{g}$ pSG5.HA-GRIP1 in the absence (closed columns) or presence (open columns) of mACTN2 $(0.25 \mu \mathrm{g})$.

Transfected cultures were grown in DMEM supplemented with $10 \%$ charcoal-treated fetal bovine serum, and luciferase activities of the transfected cell extracts were determined. Numbers above the column indicate fold activity relative to that of ER with no added coactivators. (C) HeLa cells were transiently transfected with MMTV(TRE)-LUC reporter gene $(0.3 \mu \mathrm{g})$, pCMX-hTR $\beta 1(0.01 \mu \mathrm{g})$ encoding hTR $\beta 1$, and $0.25 \mu \mathrm{g}$ pSG5.HA-GRIP1 in the absence (closed columns) or presence (open columns) of mACTN2 $(0.25 \mu \mathrm{g})$.

Transfected cultures were grown in DMEM supplemented with $10 \%$ charcoal-treated fetal bovine serum, and luciferase activities of the transfected cell extracts were determined. Numbers above the columns indicate fold activity relative to that of TR with no added coactivators. RLU: relative light units. These data $(A, B$ and C) are the average of three experiments (mean \pm S.D.; $n=3$ ). 
Table 1 The LXXLL motif of mACTN2, amino acids $72-76$, is not the only functional motif for its primary or secondary coactivator functions

Fold activation

\section{Protein(s)}

Vector $^{\mathrm{a}}$

mACTN2 ${ }_{1-894}$

mACTN2 $1-280$

mACTN2 281-700

mACTN2 $701-894$
AR+MMTV-LUC

\begin{tabular}{|c|c|}
\hline -GRIP1 & +GRIP1 \\
\hline $\begin{array}{r}1 \pm 0.2 \\
8.9+0.8\end{array}$ & $\begin{array}{r}7.6 \pm 0.6 \\
33+0.6\end{array}$ \\
\hline $6 \cdot 9 \pm 0 \cdot 6$ & $31 \pm 4$ \\
\hline $2 \cdot 1 \pm 0 \cdot 2$ & $17 \pm 2$ \\
\hline $2 \cdot 8 \pm 0 \cdot 8$ & $12 \pm 0 \cdot 4$ \\
\hline
\end{tabular}

\begin{tabular}{|c|c|}
\hline \multicolumn{2}{|c|}{ ER+MMTV(ERE)-LUC } \\
\hline -GRIP1 & +GRIP1 \\
\hline $1 \pm 0 \cdot 1$ & $30 \pm 0 \cdot 3$ \\
\hline $8 \cdot 2 \pm 0.7$ & $237 \pm 22$ \\
\hline $4.6 \pm 0.5$ & $105 \pm 9$ \\
\hline $2 \cdot 6 \pm 0 \cdot 2$ & $134 \pm 24$ \\
\hline $3.5 \pm 0.1$ & $103 \pm 16$ \\
\hline
\end{tabular}

\begin{tabular}{|c|c|}
\hline \multicolumn{2}{|c|}{ TR+MMTV(TRE)-LUC } \\
\hline -GRIP1 & + GRIP1 \\
\hline $1 \pm 0 \cdot 1$ & $13 \pm 0.6$ \\
\hline $6 \cdot 9 \pm 0 \cdot 1$ & $325 \pm 3$ \\
\hline $3 \cdot 1 \pm 0.6$ & $218 \pm 5$ \\
\hline $2.2 \pm 0.5$ & $201 \pm 28$ \\
\hline $3 \cdot 6 \pm 0.2$ & $196 \pm 9$ \\
\hline
\end{tabular}

a HeLa cells were transfected with plasmids described in Fig. 5. Other mACTN2 fragments were performed in the same conditions of full-length mACTN2 in HeLa cells. Similar activity profiles were observed in four independent experiments.

screening and co-immunoprecipitation assays (Fig. $2 \mathrm{~A}$ and data not shown). We showed that the LXXLL motif, a signature for NR coactivators, is conserved in mACTN2 and other alpha actinin family proteins, including different subfamilies and species (Fig. 4A). One of the findings in this study was the identification of a unique LXXLL motif in mACTN2 that played a major role in the interaction with AR in COS7 cells (Fig. 4B). However, the LXXLL motif of mACTN2 was shown to be a dispensable motif for its primary coactivator role in NR functions, as two truncated mACTN2s (encoding 281-700 and 701-894) lacking the LXXLL motif retained $50 \%$ or more of its coactivator function compared with full-length mACTN2 NR transcriptional activations (Table 1). Furthermore, the mutant mACTN2 (LXXAA) of full-length or amino acids 1-280 constructs retained the primary and secondary coactivator functions of wild-type mACTN2 (data not shown). These findings suggest that the primary NR coactivator of mACTN2 in NR transcription functions might act through an alternative, and as yet unknown, mechanism. At least, this conclusion is supported by our previous study, which found that the sole LXXLL motif is not an essential motif for primary NR coactivation of another GRIP1 interaction protein, Zacl (Huang \& Stallcup 2000). Therefore, an mACTN2 fragment lacking the LXXLL motif still could act as a primary coactivator through a similar mechanism to Zacl or a novel pathway. However, it remains to be investigated how mACTN2 can serve as a primary NR coactivator without a transcriptional activation domain (Fig. 3A, closed columns). In addition, the property of functional NR coactivation preference by mACTN2 could be explained by a study of the NR-binding preferences of multiple LXXLL motifs in p160 coactivators. GRIP1, a pl60 coactivator, contains at least three NR binding motifs, NR box or LXXLL. NR box II of GRIP1 prefers to interact with ER, and NR box III strongly interacts with GR and AR (Ding et al. 1998, McInerney et al. 1998). Thus, the NR selectivity by NR box in GRIP1 suggests the LXXLL motif and other unidentified domains in mACTN2 may be equally important for its physical and functional interactions in various NR systems.

\section{The synergism of mACTN2 and GRIP1 on NR functions}

In addition to revealing that mACTN2 could interact with GRIP1 and AR (Figs 2A and 4B), our studies also demonstrated that mACTN2 and GRIP1 acted synergistically in NR functions (Figs 5-7). mACTN2 not only expressed similar primary coactivator functions on $\mathrm{AR}, \mathrm{ER}$ and $\mathrm{TR}$, but also had synergistic effects with GRIP1 on these NR functions (Fig. 5). These synergy effects might be through the enhancement of GRIP1 transcriptional activities through the physical interaction between mACTN2 and GRIP1 (Fig. 2). We also detected a similar synergy effect with GRIP1 in mACTN2 (LXXAA) mutants (Fig. 7 and data not shown). Our data suggest that the full coactivation of mACTN2 might be through its LXXLL motif, GRIP1 interacting domain(s) and other unidentified functional domain(s) (Table 1), or be replaced by the redundancy of ACTN proteins in cells (Fig. 4A). Alternatively, the complexity 

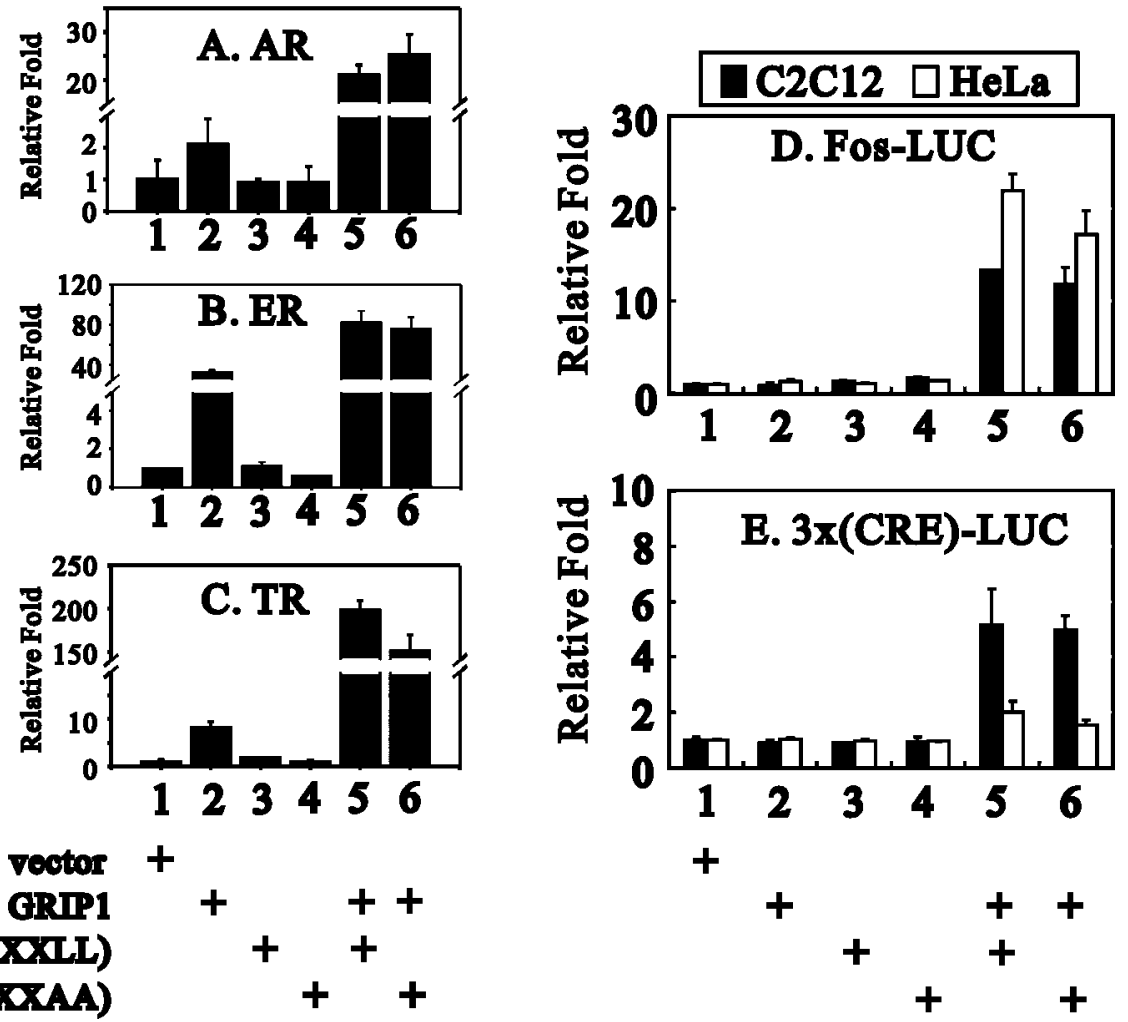

\section{ACIN2 (LXXLL) ACIN2(LXXAA)}

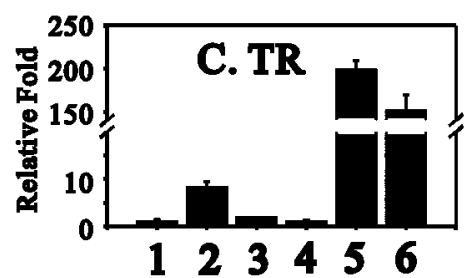

Figure 7 Functional interactions between mACTN2 and GRIP1 on receptor- and non-receptor-dependent promoters in $\mathrm{C} 2 \mathrm{C} 12$ cells. (A) $\mathrm{C} 2 \mathrm{C} 12$ cells were transiently transfected with MMTV-LUC reporter gene $(0.25 \mu \mathrm{g})$, pSVAR $(0.1 \mu \mathrm{g})$ encoding AR, and $0.325 \mu \mathrm{g}$ pSG5.HA-GRIP1, mACTN2 (wild-type or LXXAA mutant) or both in combination. Transfected cultures were grown in $10 \mathrm{nM}$ dihydrotestosterone (DHT), and luciferase activities of the transfected cell extracts were determined. Relative fold indicates fold activity relative to that of hormone-activated AR with no added coactivators. (B) C2C12 cells were transiently transfected with MMTV(ERE)-LUC reporter gene $(0.25 \mu \mathrm{g})$, pHE0 $(0.1 \mu \mathrm{g})$ encoding hER $\alpha$, and $0.325 \mu \mathrm{g}$ pSG5.HA-GRIP1, mACTN2 (wild-type or LXXAA mutant) or both in combination. Transfected cultures were grown in $10 \mathrm{nM}$ estradiol (E2) and luciferase activities of the transfected cell extracts were determined. Relative fold indicates fold activity relative to that of hormone-activated ER with no added coactivators. (C) C2C12 cells were transiently transfected with MMTV(TRE)-LUC reporter gene $(0.25 \mu \mathrm{g})$, pCMX-hTR $\beta 1(0.1 \mu \mathrm{g})$ encoding hTR $\beta 1$, and $0.325 \mu \mathrm{g}$ pSG5.HA-GRIP1, mACTN2 (wild-type or LXXAA mutant) or both in combination. Transfected cultures were grown in $10 \mathrm{nM}$ 3,5,5'-triiodo-L-thyronine $\left(T_{3}\right)$, and luciferase activities of the transfected cell extracts were determined. Relative fold indicates fold activity relative to that of hormone-activated TR with no added coactivators. (D and E) C2C12 (closed columns) and HeLa (open columns) cells were transiently transfected with Fos-LUC reporter gene $(0.3 \mu \mathrm{g})$ or $3 \times(\mathrm{CRE})$-LUC reporter gene $(0.3 \mu \mathrm{g})$ and $0.325 \mu \mathrm{g}$ pSG5.HA-GRIP1, mACTN2 (wild-type or LXXAA mutant) or both in combination. Transfected cultures were treated with $1 \mu \mathrm{g} / \mathrm{ml}$ for $20 \mathrm{~h}$ in Fos-LUC reporter gene. Luciferase activities of the transfected cell extracts were determined. Relative fold indicates fold activity relative to that with no added coactivators. These data are the average of three experiments (mean \pm S.D.; $n=3$ ).

(or conformation) level of full-length mACTN2, in vivo, might be important for its functional roles in cells because of its homodimerization difference between full-length and a fragment of amino acids
281-700 (Fig. 3A). These data suggest that other unknown regulatory factors for mACTN2 in cells may be involved in the final functional complexes among mACTN2, GRIP1 and NRs. 


\section{Selectivity and redundancy of mACTN2}

mACTN2 was not expressed in all tissues and embryo stages (Fig. 1B). The mACTN2 expression level in heart was equal to or greater than that in skeletal muscle. In addition, the regulation of muscle differentiation by some nuclear receptor coactivators implies that the coactivator role of mACTN2 and other NR coactivators might be important for the normal function or development of muscle and heart. A recent study maps the familial polymorphic ventricular arrhythmias in arrhythmogenic right ventricular cardiomyopathy to chromosome 1q42-43, in close proximity to the alpha-actinin 2 locus (Beggs et al. 1992, Bauce et al. 2000). Another study shows that p300, a coactivator of myocyte enhancer binding factor $2 \mathrm{C}$ (MEF2C), and Drosophila NK2 transcription factor related, locus 5, are two of three pivotal regulators of cardiac gene expression (Poizat et al. 2000). These two studies suggest that alpha-actinin 2 and its nuclear receptor coactivator functions might play important roles in heart development, because GRIP1 is also an important coactivator for the MEF2 family. The latest study shows that mutations in the muscle LIM protein and $\alpha$-actinin 2 genes are found in dilated cardiomyopathy and endocardial fibroelastosis (Mohapatra et al. 2003). These mutations primarily disrupt the physical interaction between the muscle LIM protein and $\alpha$-actinin 2 genes and alter the cellular localizations of these two genes in cells.

The mechanism involving mACTN2 in NR coactivator functions is still unclear. However, the subcellular localization (cytoplasm or nucleus) of mACTN2 might be a regulatory factor for its working mechanisms, because the family of $\alpha$-actinin interacts with a broad spectrum of molecules (Burridge et al. 1990, Colombo et al. 1993). Recently, an actin-binding protein, filamin, a $280 \mathrm{kDa}$ component of the cytoskeleton, was found to interact with hAR and facilitate hAR nuclear translocalization (Ozanne et al. 2000). The study by Honda et al. (1998) indicated that ACTN4 can translocate into the nucleus, depending on the cell type, inhibition of phosphatidylinositol 3 kinase or actin depolymerization. Hence, the possibility of redundant functions from other ACTN proteins and that the unidentified regulatory intracellular translocalization of mACTN2 will affect the final functional roles of mACTN2 in cells. Nonetheless, a detailed mechanistic analysis of actin-binding proteins containing the LXXLL motif, involvement in cytoskeleton remodeling and transcriptional activation by NRs could increase our understanding of how actin-filament webs influence gene expression during both normal development and pathophysiological conditions.

\section{Acknowledgements}

We thank M R Stallcup (University of Southern California, CA, USA) and G G Chang (National Yang-Ming University, Taiwan, Republic of China) for critical comments on the manuscript; P Webb, P J Kushner and W Feng (University of California, USA) for expression vectors and reporter genes for ER and TR; A O Brinkmann (Erasmus University, Rotterdam, The Netherlands) and R L Miesfeld (University of Arizona, AZ, USA) for AR expression vectors; and J K Nyborg (Colorado State University, CO, USA) for $3 \times(\mathrm{CRE})-\mathrm{LUC}$ reporter gene. This work was supported by grants from the National Science Council and National Health Research Institute, Taiwan, Republic of China (NSC 91-2320-B-016047 and NHRI-EX92-9224NG to S M Huang).

\section{References}

Bauce B, Nava A, Rampazzo A, Daliento L, Muriago M, Basso C, Thiene G \& Danieli GA 2000 Familial effort polymorphic ventricular arrhythmias in arrhythmogenic right ventricular cardiomyopathy map to chromosome 1q42-43. American fournal of Cardiology 85 573-579.

Beato M, Herrlich P \& Schutz G 1995 Steroid hormone receptors: many actors in search of a plot. Cell $\mathbf{8 3}$ 851-857.

Beggs AH, Byers TJ, Knoll JH, Boyce FM, Bruns GA \& Kunkel LM 1992 Cloning and characterization of two human skeletal muscle alpha-actinin genes located on chromosomes 1 and 11. Fournal of Biological Chemistry 267 9281-9288.

Bevan CL, Hoare S, Claessens F, Heery DM \& Parker MG 1999 The AF1 and AF2 domains of the androgen receptor interact with distinct regions of SRC1. Molecular and Cellular Biology 19 8383-8392.

Blanco JC, Minucci S, Lu J, Yang XJ, Walker KK, Chen H, Evans RM, Nakatani Y \& Ozato K 1998 The histone acetylase PCAF is a nuclear receptor coactivator. Genes and Development 12 $1638-1651$

Brinkmann AO, Faber PW, van Rooij HC, Kuiper GG, Ris C, Klaassen P, van der Korput JA, Voorhorst MM, van Laar JH \& Mulder E 1989 The human androgen receptor: domain structure, genomic organization and regulation of expression. Fournal of Steroid Biochemistry 34 307-310.

Burridge K, Nuckolls G, Otey C, Pavalko F, Simon K \& Turner G 1990 Actin-membrane interaction in focal adhesions. Cell Differentiation and Development 32 337-342. 
Chakravarti D, LaMorte VJ, Nelson MC, Nakajima T, Schulman IG, Juguilon H, Montminy M \& Evans RM 1996 Role of CBP/P300 in nuclear receptor signalling. Nature 383 99-103.

Chamberlain NL, Driver ED \& Miesfeld RL 1994 The length and location of CAG trinucleotide repeats in the androgen receptor $\mathrm{N}$-terminal domain affect transactivation function. Nucleic Acids Research 22 3181-3186.

Chen D, Ma H, Hong H, Koh SS, Huang SM, Schurter BT, Aswad DW \& Stallcup MR 1999 Regulation of transcription by a protein methyltransferase. Science $\mathbf{2 8 4} 2174-2177$.

Chen D, Huang SM \& Stallcup MR 2000 Synergistic, p160 coactivator-dependent enhancement of estrogen receptor function by CARM1 and p300. Fournal of Biological Chemistry 275 40810-40816.

Chen H, Lin RJ, Schiltz RL, Ghakravarti D, Nash A, Nagy L, Privalsky ML, Nakatani Y \& Evans RM 1997 Nuclear receptor coactivator ACTR is a novel histone acetyltransferase and forms a multimeric activation complex with $\mathrm{P} / \mathrm{CAF}$ and $\mathrm{CBP} / \mathrm{p} 300$. Cell 90 569-580.

Colombo R, DalleDonne I \& Milzani A 1993 Alpha-actinin increases actin filament end concentration by inhibiting annealing. Fournal of Molecular Biology 230 1151-1158.

Ding XF, Anderson CM, Ma H, Hong H, Uht RM, Kushner PJ \& Stallcup MR 1998 Nuclear receptor-binding sites of coactivators glucocorticoid receptor interacting protein 1 (GRIPl) and steroid receptor coactivator 1 (SRC-1): multiple motifs with different binding specificities. Molecular Endocrinology 12 302-313.

Feng W, Ribeiro RC, Wagner RL, Nguyen H, Apriletti JW, Fletterick RJ, Baxter JD, Kushner PJ \& West BL 1998 Hormone-dependent coactivator binding to a hydrophobic cleft on nuclear receptors. Science 280 1747-1749.

Freedman LP 1999 Increasing the complexity of coactivation in nuclear receptor signaling. Cell 97 5-8.

Fuse H, Kitagawa H \& Kato S 2000 Characterization of transactivational property and coactivator mediation of rat mineralocorticoid receptor activation function-1 (AF-1). Molecular Endocrinology 14 889-899.

Glass CK \& Rosenfeld MG 2000 The coregulator exchange in transcriptional functions of nuclear receptors. Genes and Development 14 121-141.

Gluzman Y 1981 SV40-transformed simian cells support the replication of early SV40 mutants. Cell 23 175-182.

Goodman RH \& Smolik S 2000 CBP/p300 in cell growth, transformation, and development. Genes and Development $\mathbf{1 4}$ $1553-1577$.

Green S, Issemann I \& Sheer E 1988 A versatile in vivo and in vitro eukaryotic expression vector for protein engineering. Nucleic Acids Research 16369.

Hance JE, Fu SY, Watkins SC, Beggs AH \& Michalak M 1999 alpha-actinin-2 is a new component of the dystrophin-glycoprotein complex. Archives of Biochemistry and Biophysics 365 216-222.

Heery DM, Kalkhoven E, Hoare S \& Parker MG 1997 A signature motif in transcriptional co-activators mediates binding to nuclear receptors. Nature 387 733-736.

Honda K, Yamada T, Endo R, Ino Y, Gotoh M, Tsuda H, Yamada Y, Chiba H \& Hirohashi S 1998 Actinin-4, a novel actin-bundling protein associated with cell motility and cancer invasion. Fournal of Cellular Biology 140 1383-1393.

Huang SM \& Stallcup MR 2000 Mouse Zac1, a transcriptional coactivator and repressor for nuclear receptors. Molecular and Cellular Biology 20 1855-1867.

Kamei Y, Xu L, Heinzel T, Torchia J, Kurokawa R, Gloss B, Lin SC, Heyman RA, Rose DW, Glass CK \& Rosenfeld MG 1996 A CBP integrator complex mediates transcriptional activation and AP-1 inhibition by nuclear receptors. Cell 85 403-414.

Koh SS, Chen D, Lee YH \& Stallcup MR 2001 Synergistic enhancement of nuclear receptor function by p160 coactivators and two coactivators with protein methyltransferase activities. Fournal of Biological Chemistry 276 1089-1098.

Kunkel TA, Roberts JD \& Zakour RA 1987 Rapid and efficient site-specific mutagenesis without phenotypic selection. Methods in Enzymology 154 367-382.

Ma H, Hong H, Huang SM, Irvine RA, Webb P, Kushner PJ, Coetzee GA \& Stallcup MR 1999 Multiple signal input and output domains of the 160-kilodalton nuclear receptor coactivator proteins. Molecular and Cellular Biology 19 6164-6173.

Mangelsdorf DJ \& Evan RM 1995 The RXR heterodimers and orphan receptors. Cell $\mathbf{8 3} 841-850$.

McInerney EM, Rose DW, Flynn SE, Westin S, Mullen TM, Krones A, Inostroza J, Torchia J, Nolte RT, Assa-Munt N, Milburn MV, Glass CK \& Rosenfeld MG 1998 Determinants of coactivator LXXLL motif specificity in nuclear receptor transcriptional activation. Genes and Development 12 3357-3368.

McKenna NJ, Xu J, Nawaz Z, Tsai SY, Tsai MJ \& O'Malley BW 1999 Nuclear receptor coactivators: multiple enzymes, multiple complexes, multiple functions. Fournal of Steroid Biochemistry and Molecular Biology 69 3-12.

Mohapatra B, Jimenez S, Lin JH, Bowles KR, Coveler KJ, Marx JG, Chrisco MA, Murphy RT, Lurie PR, Schwartz RJ, Elliott PM, Vatta M, McKenna W, Towbin JA \& Bowles NE 2003 Mutations in the mouse LIM protein and $\alpha$-actinin-2 genes in dilated cardiomyopathy and endocardial fibroelastosis. Molecular Genetics and Metabolism 80 207-215.

Oberste-Berghaus C, Zanger K, Hashimoto K, Cohen RN, Hollenberg AN \& Wondisford FE 2000 Thyroid hormone-independent interaction between the thyroid hormone receptor beta2 amino terminus and coactivators. Fournal of Biological Chemistry 275 1787-1792.

Ogryzko VV, Schiltz RL, Russanova V, Howard BH \& Nakatani Y 1996 The transcriptional coactivators p300 and CBP are histone acetyltransferases. Cell $\mathbf{8 7}$ 953-959.

Oñate SA, Boonyaratanakornkit V, Spencer TE, Tsai SY, Tsai MJ, Edwards DP \& O'Malley BW 1998 The steroid receptor coactivator-1 contains multiple receptor interacting and activation domains that cooperatively enhance the activation function 1 (AF1) and AF2 domains of steroid receptors. Fournal of Biological Chemistry 273 12101-12108.

Ozanne DM, Brady ME, Cook S, Gaughan L, Neal DE \& Robson CN 2000 Androgen receptor nuclear translocation is facilitated by the f-actin cross-linking protein filamin. Molecular Endocrinology 14 $1618-1626$.

Paech K, Webb P, Kuiper GG, Nilsson S, Gustafsson J, Kushner PJ \& Scanlan TS 1997 Differential ligand activation of estrogen receptors ERalpha and ERbeta at AP1 sites. Science 277 $1508-1510$.

Poizat C, Sartorelli V, Chung G, Kloner RA \& Kedes L 2000 Proteasome-mediated degradation of the coactivator p300 impairs cardiac transcription. Molecular and Cellular Biology 20 8643-8654.

Spengler D, Villalba M, Hoffmann A, Pantaloni C, Houssami S, Bockaert J \& Journot L 1997 Regulation of apoptosis and cell cycle arrest by Zacl, a novel zinc finger protein expressed in the pituitary gland and the brain. EMBO foumal $162814-2825$.

Strahl BD \& Allis CD 2000 The language of covalent histone modifications. Nature 403 41-45.

Swope DL, Mueller CL \& Chrivia JC 1996 CREB-binding protein activates transcription through multiple domains. Fournal of Biological Chemistry 271 28138-28145.

Torchia J, Rose DW, Inostroza J, Kamei Y, Westin S, Glass CK \& Rosenfeld MG 1997 The transcriptional co-activator p/CIP binds CBP and mediates nuclear-receptor function. Nature 387 677-684.

Tremblay A, Tremblay GB, Labrie F \& Giguere V 1999 Ligand-independent recruitment of SRC-1 to estrogen receptor beta through phosphorylation of activation function AF-1. Molecular Cell 3 513-519. 
Tsai MJ \& O'Malley BW 1994 Molecular mechanisms of action of steroid/thyroid receptor superfamily members. Annual Review of Biochemistry 63 451-486.

Umesono K \& Evans RM 1989 Determinants of target gene specificity for steroid/thyroid hormone receptors. Cell $\mathbf{5 7}$ $1139-1146$

Voegel JJ, Heine MJ, Zechel C, Chambon P \& Gronemeyer H 1996 TIF2, a $160 \mathrm{kDa}$ transcriptional mediator for the ligand-dependent activation function AF-2 of nuclear receptors. EMBO Journal 15 3667-3675.

Voegel JJ, Heine MJ, Tini M, Vivat V, Chambon P \& Gronemeyer H 1998 The coactivator TIF2 contains three nuclear receptor-binding motifs and mediates transactivation through $\mathrm{CBP}$ binding-dependent and -independent pathways. EMBO fournal 17 $507-519$.
Webb P, Nguyen P, Shinsako J, Anderson C, Feng W, Nguyen MP, Chen D, Huang SM, Subramanian S, McKinerney E, Katzenellenbogen BS, Stallcup MR \& Kushner PJ 1998 Estrogen receptor activation function 1 works by binding p160 coactivator proteins. Molecular Endocrinology 12 1605-1618.

Yao TP, Ku G, Zhou N, Scully R \& Livingston DM 1996 The nuclear hormone receptor coactivator SRC-1 is a specific target of p300. PNAS 93 10626-10631.

Received in final form 6 January 2003

Accepted 14 January 2004

Made available online as an

Accepted Preprint 21 January 2004 